\title{
Neuroprotective Effect of 4-Methylcyclopentadecanone on Focal Cerebral Ischemia/Reperfusion Injury in Rats
}

\author{
Yukui $\mathrm{Ma}^{1,2}$, Yue $\mathrm{Li}^{3}$, Chunxia Zhang ${ }^{4}$, Xiaomian Zhou ${ }^{1}$, and Yingliang $\mathrm{Wu}^{1, *}$ \\ ${ }^{1}$ Department of Pharmacology, Shenyang Pharmaceutical University, Shenyang 110015, China \\ ${ }^{2}$ Shandong Provincial Key Laboratory of Chemical Drug, Shandong Pharmaceutical Academy, Jinan 250100, China \\ ${ }^{3}$ People's Hospital of Zhangqiu City, Zhangqiu 250200, China \\ ${ }^{4}$ Jinan Maternal and Child Health Hospital, Jinan 250001, China
}

Received April 23, 2014; Accepted May 25, 2014

\begin{abstract}
The present study aimed to investigate the effect of 4-methylcyclopentadecanone (4-MCPC) on local cerebral ischemia-reperfusion and the possible mechanisms involved. For this purpose, the focal cerebral ischemia rat model was induced by middle cerebral artery occlusion (MCAO) for $2 \mathrm{~h}$, and the rats were treated with 4-MCPC (4 or $8 \mathrm{mg} \cdot \mathrm{kg}^{-1}$, p.o.) just $0.5 \mathrm{~h}$ before reperfusion. The neurological deficit scores and the ischemic infarct volume were recorded $24 \mathrm{~h}$ after the MCAO. In addition, the number of apoptotic cells was measured by TUNEL assay, and the expression of apoptosis-regulatory proteins and the PI3K/Akt neuroprotective signaling pathway were investigated by western blotting. Our results indicated that 4-MCPC ( 4 or $8 \mathrm{mg} \cdot \mathrm{kg}^{-1}$ ) remarkably alleviated cerebral $\mathrm{I} / \mathrm{R}$ injury by decreasing infarct volume and neurological deficit scores. 4-MCPC also decreased the number of apoptotic cells, regulated the expression of Bcl-2 and Bax, and increased the ratio of Bcl-2/Bax. Further study revealed that 4-MCPC treatment also increased the level of $\mathrm{p}-\mathrm{Akt}$ and $\mathrm{p}-\mathrm{GSK}-3 \beta$. Wortmannin (PI3K inhibitor) markedly abolished the effects of 4-MCPC. Taken together, our results suggest that 4-MCPC protects against cerebral I/R injury through the inhibition of apoptosis, and this neuroprotective effect may be partly related to the activation of the PI3K/Akt signal pathway.
\end{abstract}

Keywords: 4-methylcyclopentadecanone, apoptosis, Akt, GSK-3 $\beta$, ischemia/reperfusion

\section{Introduction}

Stroke is the third most common cause of death in industrialized countries (1), and it is considered the most common disability in adults (2). It is estimated that $60 \%-70 \%$ of all stroke victims suffer an ischemic stroke (3). Ischemic stroke primarily involves occlusion of blood vessels in the brain, and rapid reperfusion of occluded cerebral blood vessels is the most effective treatment for ischemic stroke. However, restoration of cerebral blood flow can cause further damage to brain, such as brain hemorrhage, cerebral edema, and neuronal death (4). This phenomenon is called cerebral ischemia/ reperfusion (I/R) injury (5).

*Corresponding author. yaoliduli@163.com Published online in J-STAGE on July 2, 2014 doi: $10.1254 /$ jphs.14102FP
The pathogenesis of I/R injury includes excitotoxicity, calcium overload, oxidative stress, inflammation, lipid peroxidation, apoptosis, etc. $(6,7)$. Apoptosis is one of the major causes of cell death after cerebral ischemia (8). The phosphatidylinositol-3 kinase/Akt (PI3K/Akt) pathway is involved in apoptotic signal transduction, and it plays a vital role in the neuroprotective effect of ischemic post-conditioning (9). Akt is activated by phosphorylated PI3K, and it can phosphorylate glycogen synthase kinase-3beta (GSK-3 $\beta$ ), which modulates key steps in the major apoptotic signaling pathways $(10,11)$. The Bcl-2 family of proteins is downstream of the $\mathrm{PI} 3 \mathrm{~K} /$ Akt signaling pathway. The balance between the two main classes of Bcl-2 family proteins, such as Bcl-2 (antiapoptotic) and Bax (proapoptotic), critically regulate apoptosis (12). It has been suggested that apoptotic cell death in response to $I / R$ injury can be regulated by the balance of Bcl-2 and Bax. 
Musk has been widely used in China for thousands of years as a refreshing agent that promotes blood flow and detumescence. Muscone was believed to be the main active ingredient of musk, and its molecular formula was recognized as 3-methylcyclopentadecanone (13). Modern research in animals has shown that muscone has protective effects on ischemia/reperfusion injury in cardiac myocytes (14) and provides neuroprotective effects against cerebral anoxia and ischemia (15). 4Methylcyclopentadecanone (4-MCPC) is a by-product of the synthesis process of muscone that was discarded in the past. Experimental studies have shown that 4-MCPC has similar effects on antiinflammation, antidementia, and antioxidation as muscone $(16,17)$, and it was used to treat ischemic cerebrovascular disease in a patent in China. However, the neuroprotective effects and the associated mechanisms of 4-MCPC have not been explored in an $\mathrm{I} / \mathrm{R}$ injury model. This is the first report of the effects of 4-MCPC on local cerebral I/R injury in rats.

\section{Materials and Methods}

\section{Animals}

Male Sprague-Dawley rats, weighing 250-280 g, were purchased from Vital River Laboratory Animal Technology Co., Ltd. (Beijing, China). The rats were housed in a room with a $12 \mathrm{~h}$ light/dark cycle (temperature of $23^{\circ} \mathrm{C}-25^{\circ} \mathrm{C}$ and humidity of $50 \%-60 \%$ ). The rats were provided access to standard laboratory rodent chow and water ad libitum. The rats were acclimated to the animal facility for at least one week before being used in experiments. All animal related procedures were approved by the Institutional Animal Care and Use Committee (IACUC) of Shandong Pharmaceutical Academy.

Rats were randomly divided into 5 groups: sham group, I/R group; 4-MCPC $\left(8 \mathrm{mg} \cdot \mathrm{kg}^{-1}\right)$ plus wortmannin group; 4, $8 \mathrm{mg} \cdot \mathrm{kg}^{-1}$ dose of 4-MCPC group (the doses were chosen from a trial test and the previous study by Zhang et al. (16).

\section{Materials}

4-MCPC was provided by Shandong Hongjitang Pharmaceutical Group Co., Ltd. (Jinan, China). All the tested articles were suspended in 1\% sodium carboxymethylcellulose (CMC-Na) suspension in distilled water at the required concentrations, respectively. Wortmannin was dissolved in $1 \%$ dimethyl sulfoxide (DMSO) in normal saline (NS) at the concentration of $100 \mathrm{nM}$. Antibodies against Akt, p-Akt (Ser473), GSK-3 $\beta$, and p-GSK-3 $\beta$ (Ser9) were obtained from Cell Signaling Technology (Beverly, MA, USA). Antibodies to Bcl-2,
Bax, GAPDH, anti-mouse-horseradish peroxide (HRP)$\mathrm{IgG}$, and anti-rabbit-HRP-IgG were obtained from Santa Cruz Biotechnology (Santa Cruz, CA, USA). Wortmannin (PI3K inhibitor) was purchased from Gene Operation (Ann Arbor, Michigan, USA). TUNEL detection kit was purchased from Nanjing Keygen Technology Development Co., Ltd. (Nanjing, China).

\section{Focal cerebral ischemia model}

Focal cerebral ischemia was induced by the middle cerebral artery occlusion (MCAO) procedure, as previously described (18). Briefly, animals were anesthetized by intraperitoneal injection of $2 \%$ chloral hydrate $\left(350 \mathrm{mg} \cdot \mathrm{kg}^{-1}\right)$, and body temperature was maintained at $37^{\circ} \mathrm{C} \pm 0.5^{\circ} \mathrm{C}$ with infrared heat and a heating pad during the period of anesthesia. After the skin was incised, the right common carotid artery (CCA), external carotid artery (ECA), and internal carotid artery (ICA) were carefully stripped. A 4-0 nylon monofilament (Ethicon, Inc., Osaka) was inserted through the incision into the lumen of the right ICA to occlude the right middle cerebral artery. 4-MCPC was administered by gastric perfusion just $0.5 \mathrm{~h}$ before reperfusion and the rats of sham and $\mathrm{I} / \mathrm{R}$ group were given $1 \% \mathrm{CMC}-\mathrm{Na}$. Wortmannin $(10 \mu \mathrm{L})$ was injected into the lateral ventricle $(0.5 \mathrm{~mm}$ from posterior, $1.4 \mathrm{~mm}$ lateral to the bregma, and $3.1 \mathrm{~mm}$ from the duramater) using a stereotaxic instrument and injector (Stoelting Co., Wood Dale, IL, USA). Except for the group of 4-MCPC plus wortmannin, other groups were administrated with $1 \%$ DMSO. After $2 \mathrm{~h}$ of occlusion, the suture was withdrawn carefully from the ICA and reperfusion was accomplished. Then, the neck incision was closed and the rats were allowed to wake up.

\section{Neurological deficit scoring evaluation}

Twenty-four hours after the MCAO, neurological deficits were evaluated according to Longa's method (19). The scoring system was based on a 5-point scale: 0 , no neurological deficit; 1 , failure to stretch the left forepaw fully; 2 , rotating to the right; 3 , leaning to the left when walking; 4, no spontaneous activities or death. The rats were scored between 0 or 4 points after the MCAO was removed.

\section{Detection of ischemic infarct volume}

After evaluation of neurological deficit, the rats were anesthetized and sacrificed. The brains were removed quickly and kept at $-20^{\circ} \mathrm{C}$ for $10 \mathrm{~min}$. Frozen brains were sliced into 2-mm coronal sections and stained with $2 \%$ solution of 2,3,5-triphenyltetrazolium chloride (TTC) at $37^{\circ} \mathrm{C}$ for $30 \mathrm{~min}$. After staining, the coronal section was fixed in $4 \%$ paraformaldehyde for $24 \mathrm{~h}$. The stained 
sections were photographed using a digital camera with high-resolution, and the infarct area was measured using a computerized image analysis system. The percentage of infarct volume was measured by calculating the percentage of infarct volume in the ipsilateral hemispheric volume (total infarct volume/ipsilateral hemispheric volume $\times 100 \%)$.

\section{TUNEL staining}

TUNEL assay was performed to measure the number of apoptotic cells. Rats were anesthetized $24 \mathrm{~h}$ after reperfusion and perfused with freshly prepared $4 \%$ paraformaldehyde. The brain was removed and fixed in $10 \%$ formaldehyde for one week. Then, the brain was cut into 5- $\mu \mathrm{m}$-thick coronal sections and placed on adhesive glass. TUNEL staining was carried out by using a TUNEL detection kit according to the kit instructions. The cells displaying brown staining within the nucleus were considered as apoptotic cells. An examiner kept unaware of the group assignment counted the number of apoptotic cells throughout 5 lesion regions randomly in the peri-infarct cortex under an inverted microscope (Olympus CX31; Olympus, Tokyo).

\section{Western blot analysis}

Western blotting was performed as described previously (20). Briefly, rats from each group $(n=4)$ were anesthetized and sacrificed $24 \mathrm{~h}$ after reperfusion. The brains were removed quickly at $4^{\circ} \mathrm{C}$, and ischemic brain tissues were isolated and homogenized in lysis buffer (50 mM Tris, $150 \mathrm{mM} \mathrm{NaCl}, 1 \mathrm{mM}$ EDTA, $1 \%$ NP 40, $0.5 \%$ sodium deoxycholate, $0.1 \%$ SDS with $10 \mu \mathrm{g} / \mathrm{ml}$ leupeptin, $10 \mu \mathrm{g} / \mathrm{ml}$ aprotinin, $1 \mathrm{mM}$ benzamidine, $1 \mathrm{mM}$ AEBSF, $50 \mathrm{mM}$ sodium fluoride, $1 \mathrm{mM}$ sodium orthovanadate). After centrifugation $(2000 \times g, 5 \mathrm{~min}$, $4{ }^{\circ} \mathrm{C}$ ), the protein concentrations of the supernatants were determined using a BCA protein assay reagent kit (Beyotime, Haimen, China). Protein was separated by SDS/PAGE and transferred to a nitrocellulose membrane. The membranes were blocked with 5\% non-fat milk and incubated overnight at $4{ }^{\circ} \mathrm{C}$ with the following primary antibodies: anti-Akt (1:1000), antiGSK-3 $\beta$ (1:1000), anti-Bax (1:200), and anti-Bcl-2 (1:200). After washing, the membranes were incubated for $1 \mathrm{~h}$ at room temperature with the proper secondary antibodies, and then washed 3 times with TBS-T solution. Immunoblots were developed using an enhanced chemiluminescent (ECL) detection kit (Pierce, Rockford IL, USA). Relative band densities were measured with ID Image Analysis Software (GE Amersham, Piscataway, NJ, USA).

\section{Statistical analyses}

All data were analyzed using SPSS 13.0, and the values are expressed as the mean \pm standard deviation (S.D.). The data were analyzed using one-way analysis of variance (ANOVA). The neurological defect scores were analyzed using the Kruskall-Wallis H-test. $P<0.05$ was considered statistically significant.

\section{Results}

Neurological deficit scores and ischemic infarct volumes

Neurological deficit scores were assessed $24 \mathrm{~h}$ after the MCAO in the sham, I/R, 4-MCPC-treated groups, and 4-MCPC (8 $\left.\mathrm{mg} \cdot \mathrm{kg}^{-1}\right)$ plus wortmannin group (Fig. 1A). There were no significant neurological deficits in the sham group. However, severe deficits were observed in the I/R group, indicating that the I/R injury model was successfully established. The scores of the groups treated with $4 \mathrm{mg} \cdot \mathrm{kg}^{-1}$ and $8 \mathrm{mg} \cdot \mathrm{kg}^{-1} 4-\mathrm{MCPC}$ were $1.88 \pm 0.57(P<0.01)$ and $1.29 \pm 0.45(P<0.01)$, respectively, which are both significantly lower than that of the I/R group $(2.67 \pm 0.49)$. As shown in Fig. 1, $\mathrm{B}$ and $\mathrm{C}$, compared with the $\mathrm{I} / \mathrm{R}$ group $(38.98 \pm 10.78)$, infarct volumes in the 4-MCPC-treated groups were reduced by approximately $26.9 \%(12.10 \pm 6.93, P<0.01)$ for the $8 \mathrm{mg} \cdot \mathrm{kg}^{-1}$ group and $18.1 \%(20.85 \pm 6.56$, $P<0.01)$ for the $4 \mathrm{mg} \cdot \mathrm{kg}^{-1}$ group, indicating that 4-MCPC (4 or $8 \mathrm{mg} \cdot \mathrm{kg}^{-1}$, p.o.) significantly protects against cerebral $\mathrm{I} / \mathrm{R}$ injury. Furthermore, there was a significant difference in the neurological deficit scores and ischemic infarct volumes between the $4 \mathrm{mg} \cdot \mathrm{kg}^{-1}$ and $8 \mathrm{mg} \cdot \mathrm{kg}^{-1} 4-\mathrm{MCPC}$ groups $(P<0.05)$. In addition, there was significant differences in the neurological deficit scores and ischemic infarct volumes between the $8 \mathrm{mg} \cdot \mathrm{kg}^{-1} 4$-MCPC group and 4-MCPC plus wortmannin group $(P<0.01)$, and there was no significant differences between the I/R group and 4-MCPC plus wortmannin group $(P>0.05)$, indicating that Wortmannin blocked the effects of 4-MCPC.

\section{Effects on TUNEL staining}

As shown in Fig. 2, the number of apoptotic cells in the penumbral cortex in rats of the $I / R$ group was increased significantly compared with the sham group $(P<0.01)$. After treatment with $4-\mathrm{MCPC}\left(4 \mathrm{mg} \cdot \mathrm{kg}^{-1}\right.$ and $8 \mathrm{mg} \cdot \mathrm{kg}^{-1}$, p.o.), the number of apoptotic cells decreased markedly compared with the I/R group. Furthermore, there was significant difference in the number of apoptotic cells between the $8 \mathrm{mg} \cdot \mathrm{kg}^{-1} 4-\mathrm{MCPC}$ group and 4-MCPC plus wortmannin group $(P<0.01)$, and there was no significant differences between the $\mathrm{I} / \mathrm{R}$ group and 4-MCPC plus wortmannin group $(P>0.05)$. These data clearly indicated that 4 -MCPC (4 or 8 

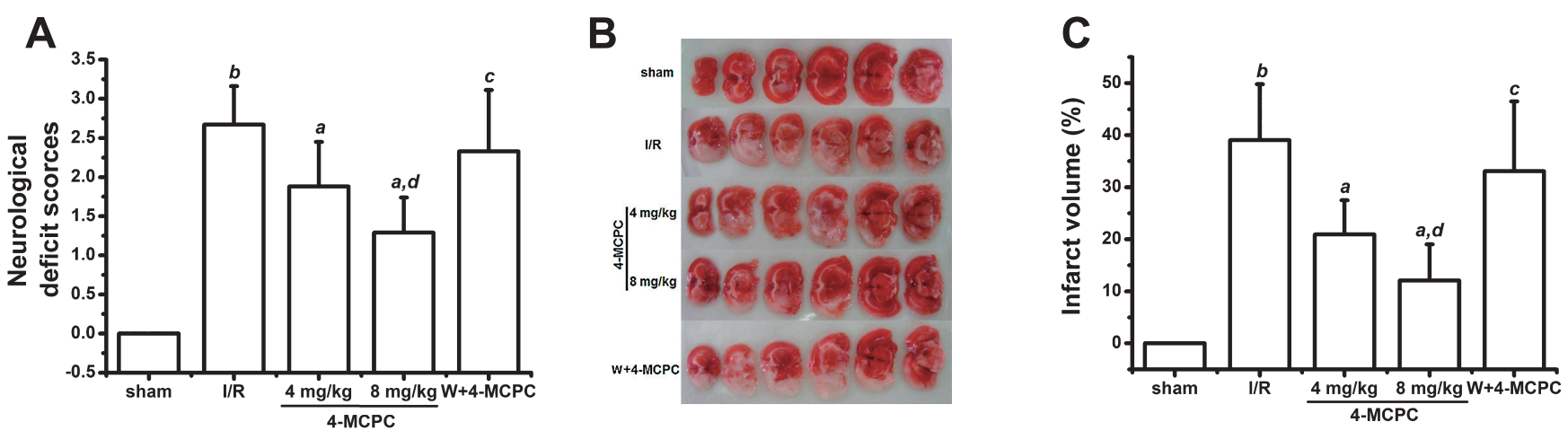

Fig. 1. 4-MCPC-treatment improved focal cerebral I/R injury and decreased neurological deficit scores and ischemic infarct volume. A) 4-MCPC treatment improved neurological deficit scores according to a 5-points scale system. B) The representative TTC-stained coronal brain sections of rats treated with 4-MCPC (4 and $\left.8 \mathrm{mg} \cdot \mathrm{kg}^{-1}\right)$. C) Quantification of ischemic infarct volume. Each group: $\mathrm{n}=12$. Bars represent the mean \pm S.D. for each group. ${ }^{\mathrm{a}} P<0.01$ vs. I/R group, ${ }^{\mathrm{b}} P<0.01$ vs. sham group, ${ }^{\mathrm{c}} P<0.01$ vs. $4-\mathrm{MCPC}\left(8 \mathrm{mg} \cdot \mathrm{kg}^{-1}\right)$ group, ${ }^{\mathrm{d}} P<0.05 \mathrm{vs} .4-\mathrm{MCPC}\left(4 \mathrm{mg} \cdot \mathrm{kg}^{-1}\right)$ group.
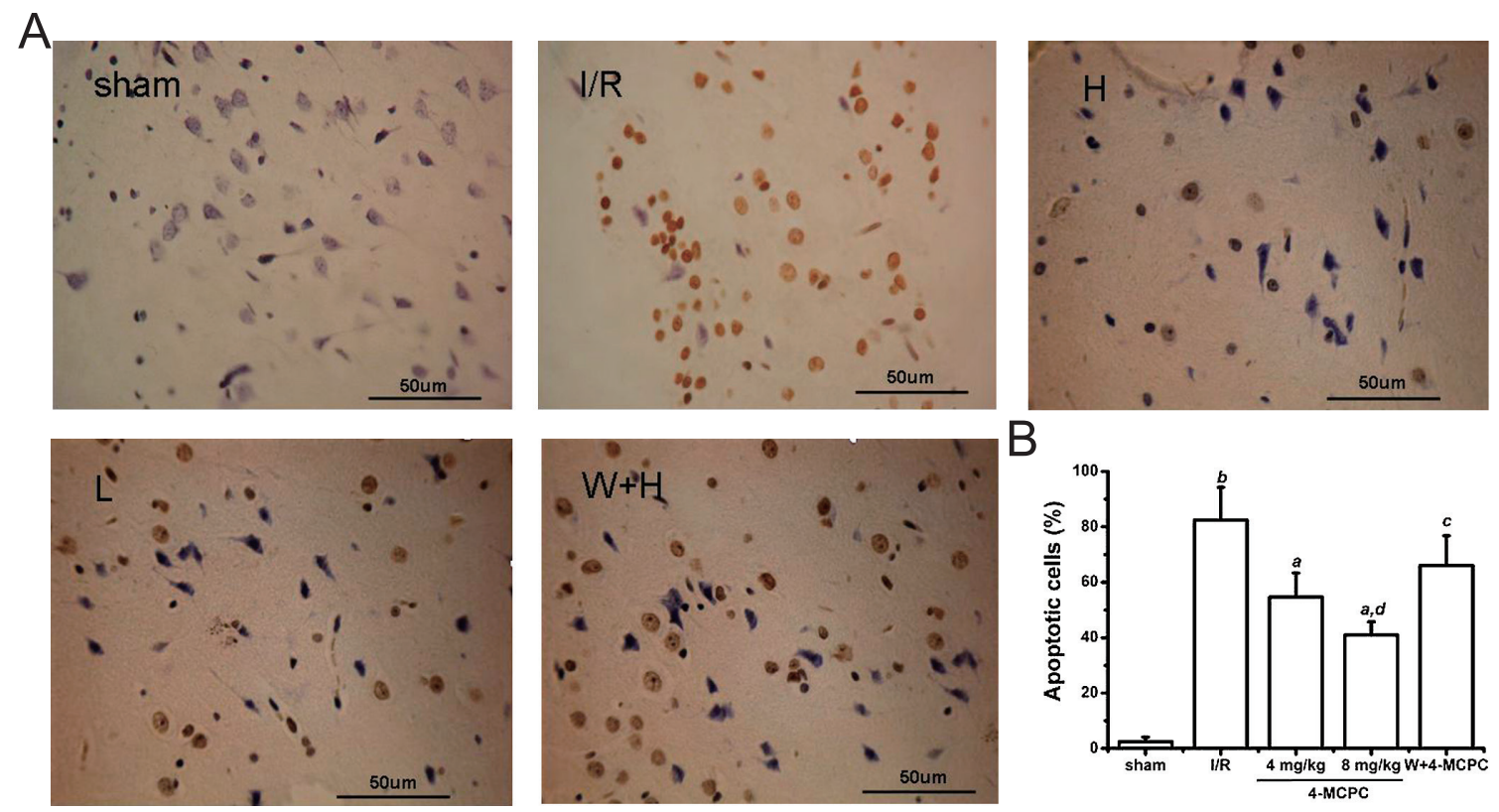

Fig. 2. 4-MCPC inhibited cell apoptosis induced by cerebral $\mathrm{I} / \mathrm{R}$ and wortmannin blocked the effects of 4-MCPC. A) TUNEL staining of the ischemic penumbra cortex of each group, B) Percentage of apoptotic cells in the ischemic penumbra cortex of each group. Each group: $\mathrm{n}=12 .{ }^{\mathrm{a}} P<0.01 \mathrm{vs.} \mathrm{I/R}$ group, ${ }^{\mathrm{b}} P<0.01$ vs. sham group, ${ }^{\mathrm{c}} P<0.01 \mathrm{vs.} 4-\mathrm{MCPC}\left(8 \mathrm{mg} \cdot \mathrm{kg}^{-1}\right)$ group, ${ }^{\mathrm{d}} P<0.05$ vs. 4 -MCPC $\left(4 \mathrm{mg} \cdot \mathrm{kg}^{-1}\right)$ group. $\mathrm{H}=4-\mathrm{MCPC}\left(8 \mathrm{mg} \cdot \mathrm{kg}^{-1}\right) ; \mathrm{L}=4-\mathrm{MCPC}\left(4 \mathrm{mg} \cdot \mathrm{kg}^{-1}\right) ; \mathrm{W}+\mathrm{H}=$ Wortmannin plus MCPC $\left(8 \mathrm{mg} \cdot \mathrm{kg}^{-1}\right)$.

$\mathrm{mg} \cdot \mathrm{kg}^{-1}$, p.o.) inhibited cell apoptosis induced by cerebral I/R and wortmannin blocked the effects of 4-MCPC.

\section{Effects on Bax and Bcl-2 expression}

To explore the mechanisms by which 4-MCPC elicits its anti-apoptotic effects, the expression levels of Bax and Bcl-2 were examined by western blotting (Fig. 3). Compared with the sham group, the I/R group displayed higher constitutive expression of Bax and lower expres- sion of Bcl-2 $(P<0.01)$. Importantly, the Bcl-2/Bax ratio was decreased in the I/R group $(P<0.01)$ (Fig. 3E). Compared with the I/R group, the 4-MCPC (4 or 8 $\mathrm{mg} \cdot \mathrm{kg}^{-1}$, p.o.)-treatment groups displayed markedly increased Bcl-2 $(P<0.01)$ (Fig. 3: A and B) and decreased Bax levels $(P<0.01)$ (Fig. 3: C and D). Correspondingly, the ratio of $\mathrm{Bcl}-2 / \mathrm{Bax}$ was drastically increased in the 4-MCPC-treated rats $(P<0.01)$ (Fig. 3E). Administration of wortmannin partly abolished the 

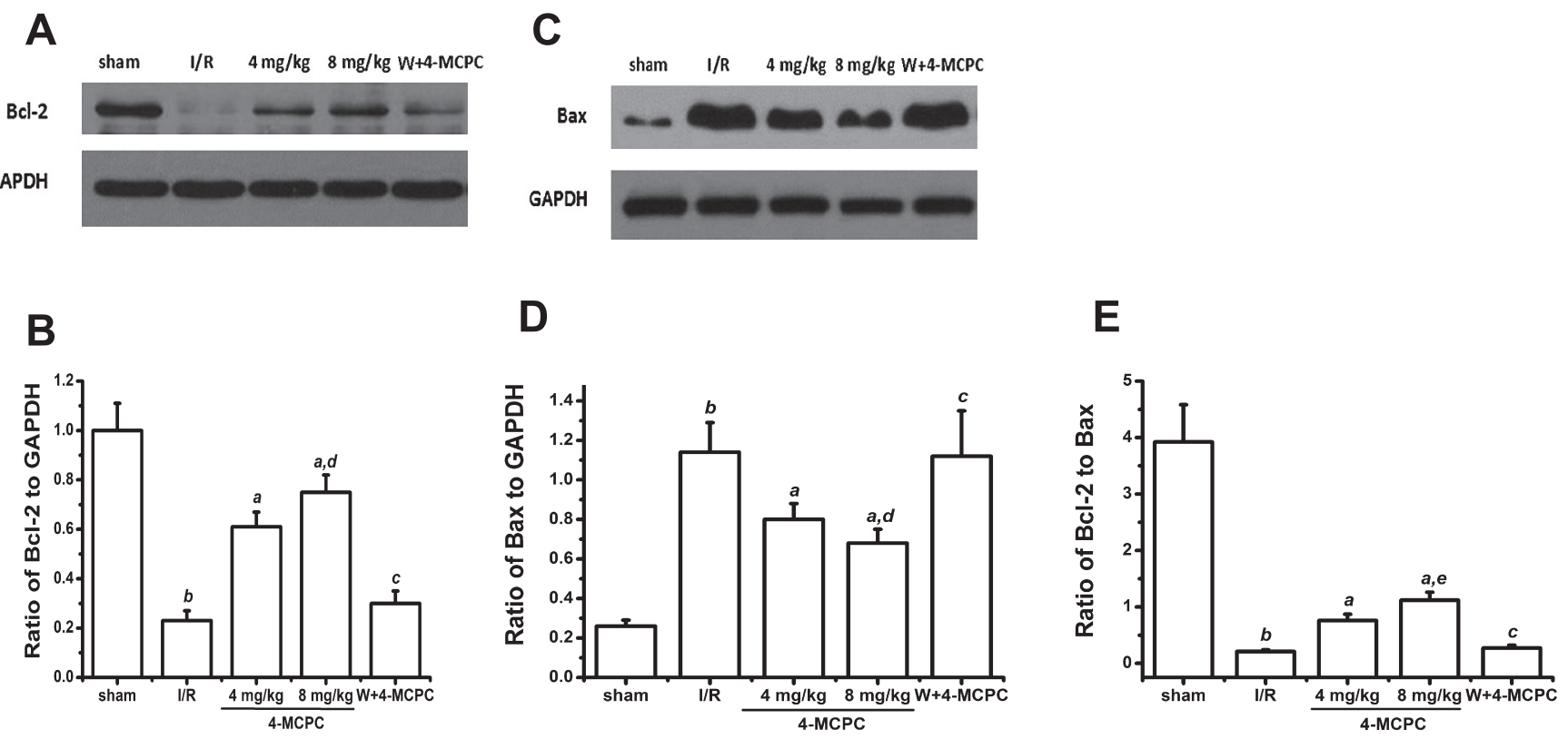

Fig. 3. 4-MCPC treatment remarkably increased the Bcl-2/Bax ratio by increasing Bcl-2 and decreasing Bax $24 \mathrm{~h}$ after the MCAO. Representative photographs showed the levels of Bcl-2 and Bax (A and C). Bcl-2 and Bax levels and relative optical density normalized to GAPDH (B and D). The quantitative analysis of Bcl-2/Bax ratio (E). Bars represent the mean \pm S.D. for samples from 4 brains in each group. ${ }^{\mathrm{a}} P<0.01$ vs. I/R group; ${ }^{\mathrm{b}} P<0.01$ vs. sham group; ${ }^{\mathrm{c}} P<0.01 \mathrm{vs.} 4-\mathrm{MCPC}\left(8 \mathrm{mg} \cdot \mathrm{kg}^{-1}\right)$ group; ${ }^{\mathrm{d}} P<0.05,{ }^{\mathrm{e}} \mathrm{P}<0.01$ vs. $4-\mathrm{MCPC}\left(4 \mathrm{mg} \cdot \mathrm{kg}^{-1}\right)$ group.

decrease of Bax levels, the increase of Bcl-2 levels, and the ratio of Bcl-2/Bax induced by $4-\mathrm{MCPC}\left(8 \mathrm{mg} \cdot \mathrm{kg}^{-1}\right)$ as compared with the 4-MCPC $\left(8 \mathrm{mg} \cdot \mathrm{kg}^{-1}\right)$ group $(P<0.01)$.

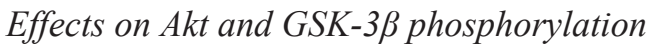

To explore the potential intracellular signaling mechanisms involved in the neuroprotective effects of 4-MCPC, we examined the PI3K/Akt pathway $24 \mathrm{~h}$ after reperfusion by monitoring the levels of phosphorylated Akt (p-Akt), total Akt (t-Akt), and p-GSK-3 $\beta$. Compared with the sham group, $\mathrm{I} / \mathrm{R}$ injury decreased $\mathrm{p}$-Akt and p-GSK-3 $\beta$ levels $(P<0.01)$, while t-Akt levels did not change $(P>0.05)$. 4-MCPC (4 or $8 \mathrm{mg} \cdot \mathrm{kg}^{-1}$, p.o.) treatment significantly increased $\mathrm{p}$-Akt and $\mathrm{p}-\mathrm{GSK}-3 \beta$ level $(P<0.01)$ (Fig. 4) compared to the I/R group. There were significant differences in the levels of p-Akt and $\mathrm{p}-\mathrm{GSK}-3 \beta$ between the 4 and $8 \mathrm{mg} \cdot \mathrm{kg}^{-1} 4-\mathrm{MCPC}$ treatment groups $(P<0.05$ or $P<0.01)$. 4-MCPC $(8$ $\left.\mathrm{mg} \cdot \mathrm{kg}^{-1}\right)$ treatment did not increase $\mathrm{p}$-Akt and $\mathrm{p}$-GSK-3 $\beta$ levels compared to the $\mathrm{I} / \mathrm{R}$ group after wortmannin pretreatment $(P>0.05)$. Furthermore, there was significant difference in the levels of p-Akt and p-GSK-3 $\beta$ between the $8 \mathrm{mg} \cdot \mathrm{kg}^{-1} 4-\mathrm{MCPC}$ group and 4-MCPC plus wortmannin group $(P<0.01)$.

\section{Discussion}

Ischemic stroke is a major cause of morbidity and mortality worldwide; however, effective therapeutic strategies to treat ischemic brain injury are still very limited. Neuroprotection is considered a promising strategy for ischemic stroke treatment. As a result, searching for neuroprotective agents has attracted increasing attention. In this study, we explored the neuroprotective effects and the underlying mechanisms of action of 4-MCPC on local cerebral I/R injury in rats by MCAO to investigate its potential utility as a treatment for ischemic stroke.

In the present study, we are the first to demonstrate that 4-MCPC (4 or $8 \mathrm{mg} \cdot \mathrm{kg}^{-1}$, p.o.) has neuroprotective effects on local cerebral $\mathrm{I} / \mathrm{R}$ Injury in a rat model, as it improved neurological deficits and reduced infarct volume (Fig. 1). Our data also demonstrated that 4MCPC inhibits apoptosis by regulating the expression of Bcl-2 and Bax and increasing the ratio of Bcl-2/Bax $24 \mathrm{~h}$ after the MCAO (Fig. 3). In addition, our data reveal that the PI3K/Akt pathway is involved in the neuroprotective mechanisms of 4-MCPC on cerebral I/R injury (Fig. 4).

MCAO is a classical model of cerebral ischemia (19). Twenty-four hours after MCAO, extensive focal cerebral tissue infarction and serious neurological deficits were 
A

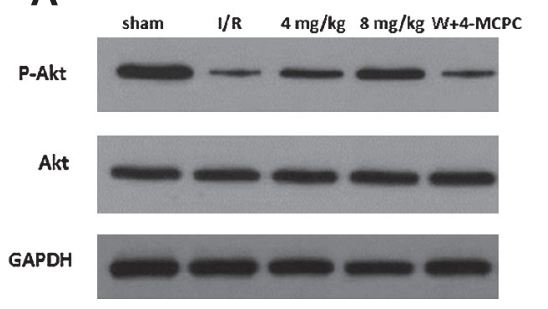

B

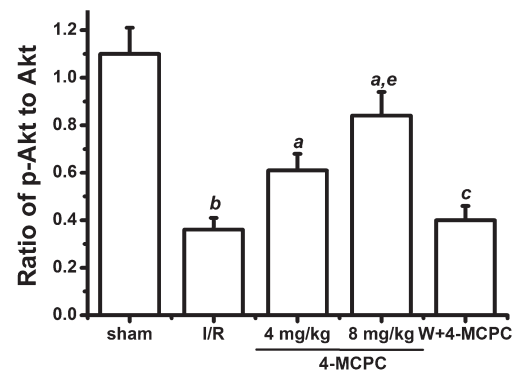

C

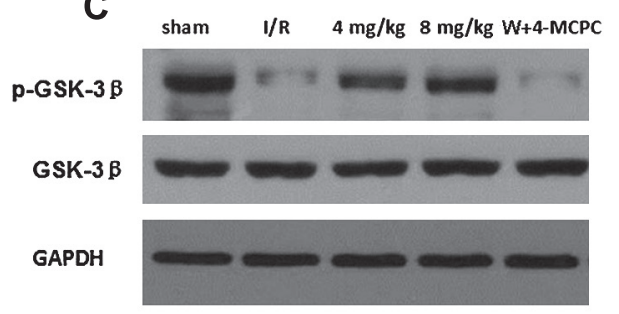

D

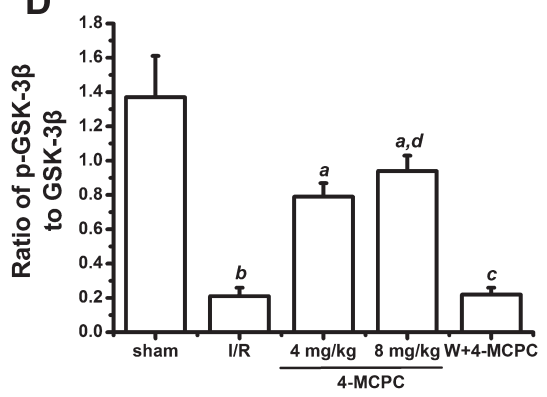

Fig. 4. Effect of 4-MCPC on Akt, p-Akt, GSK- $3 \beta$, and p-GSK- $3 \beta$ levels in the ischemic penumbra cortex $24 \mathrm{~h}$ after the MCAO. Administration of 4-MCPC (4 and $8 \mathrm{mg} \cdot \mathrm{kg}^{-1}$ ) remarkably increased $\mathrm{p}-\mathrm{Akt}$ and $\mathrm{p}-\mathrm{GSK}-3 \beta$ compared with that of the I/R group. For each group, $\mathrm{n}=4$. ${ }^{\mathrm{a}} P<0.01$ vs. I/R group; ${ }^{\mathrm{b}} P<0.01$ vs. sham group; ${ }^{\mathrm{c}} P<0.01$ vs. 4 -MCPC ( 8 $\left.\mathrm{mg} \cdot \mathrm{kg}^{-1}\right)$ group; ${ }^{\mathrm{d}} P<0.05, \quad{ }^{\mathrm{e}} P<0.01 \quad$ vs. 4-MCPC (4 $\left.\mathrm{mg} \cdot \mathrm{kg}^{-1}\right)$ group. observed (21), as determined by neurological deficit scores (22) and infarct volume. Therefore, we adopted the most commonly used neurological tests to evaluate brain tissue damage and dysneuria following focal cerebral $\mathrm{I} / \mathrm{R}$ in rats. In this study, the $\mathrm{I} / \mathrm{R}$ injury model was established successfully by inducing cerebral ischemia for $2 \mathrm{~h}$, followed by reperfusion after $24 \mathrm{~h}$. This model significantly increased neurological deficits and total infarct volume compared with the sham group. We also found that administration of 4-MCPC (4 or 8 $\mathrm{mg} \cdot \mathrm{kg}^{-1}$, p.o.) remarkably decreased neurological deficit scores and total infarct volume compared to the model group, suggesting that 4-MCPC provides dramatic neuroprotection in cerebral I/R injury.

It has been reported that transient cerebral ischemia can induce the expression of apoptotic-regulatory genes, including Bax, Bcl-2, Bcl-xl, and Bcl-w in the cortex and hippocampus (23). Among these genes, Bax and Bcl-2 are the most vital genes regulating cellular apoptosis. Bcl-2 is an anti-apoptotic protein that affects the mitochondrial outer membrane. Bcl-2 prevents cytochrome $\mathrm{C}$ from releasing into the cytoplasm, which is a vital step in the apoptotic process $(24,25)$. Targeted disruption of the Bcl-2 gene in mice exacerbates focal cerebral ischemic injury (26). In contrast, Bax is a proapoptotic protein that has significant sequence homology with Bcl-2, and activated Bax accelerates programmed cell death (27). It was previously reported that Bax levels increased in both the hippocampus and striatum at $24 \mathrm{~h}$ after cerebral ischemia (28). Bcl-2 and Bax regulate apoptosis by forming homodimers and heterodimers. Excessive expression of Bax leads to the formation of homodimers and the induction of apoptosis. In contrast, excessive expression of Bcl-2 leads to the formation of heterodimers that inhibit the apoptosis induced by Bax homodimers (29). Thus, the ratio of $\mathrm{Bcl}-2 / \mathrm{Bax}$ regulates apoptotic cell death in response to I/R injury. Our results proved that cerebral $\mathrm{I} / \mathrm{R}$ injury decreased Bcl-2 levels, increased Bax levels, and consequently decreased the Bcl-2/Bax ratio in the penumbra cortex, which was consistent with the previous reports $(20,30)$. We also studied the participation of Bax and Bcl-2 in the neuroprotective effects of 4-MCPC in I/R injury. Compared with the I/R group, treatment with 4-MCPC remarkably increased the $\mathrm{Bcl}-2 / \mathrm{Bax}$ ratio by increasing $\mathrm{Bcl}-2$ levels and decreasing Bax levels. This phenomenon might be because 4-MCPC administration up-regulated the expression of the $\mathrm{Bcl}-2$ gene and down-regulated the expression of the Bax gene. Thus, our findings suggested that 4-MCPC inhibits cranial nerve cell apoptosis after I/R.

Our findings demonstrated that 4-MCPC has a neuroprotective effect; however, the signaling pathways associated with 4-MCPC treatment remain unknown. Therefore, we further examined the role of the PI3K pathway in the neuroprotective effect of 4-MCPC in I/R injury. It was well known that the PI3K/Akt pathway plays an important role in cerebral cell apoptosis after I/R $(9,31,32)$. Previous studies indicated that the PI3K/ Akt signal pathway is inhibited during cell apoptosis by up-regulating the expression of Bcl-2 (33). Akt activation promotes cell survival by phosphorylating its several downstream target proteins, such as Bcl-2 family members, glycogen synthase kinase-3 beta (GSK-3 $\beta$ ), procaspase-9, and forehead transcription factor (FKHR) $(34,35)$. GSK- $3 \beta$ is a downstream target of the PI3K 


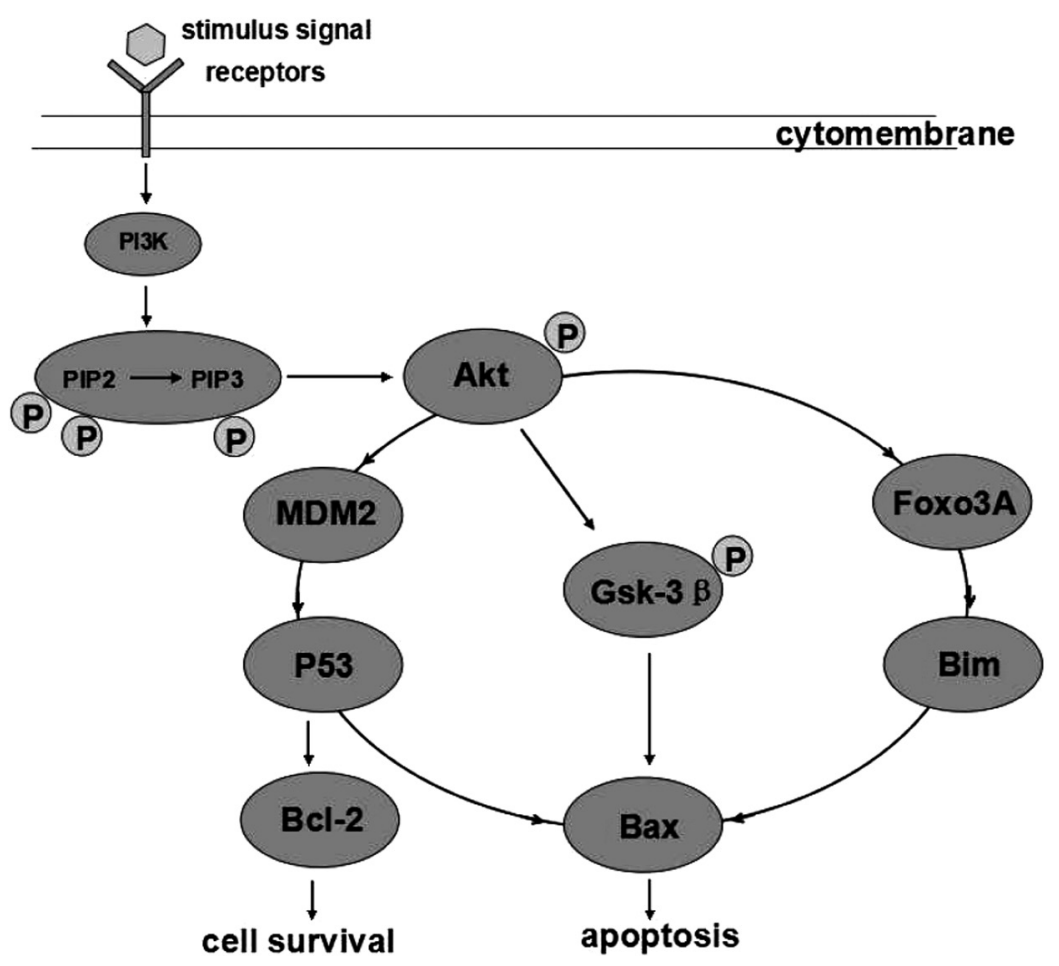

Fig. 5. Diagrammatic presentation showing the relationship between the PI3K/Akt signaling pathway and Akt, GSK-3 $\beta$, Box, Bcl-2, etc.

pathway, and it is over expressed after transient brain ischemia and exacerbates ischemic neuronal death. Phosphorylation of Akt ( $\mathrm{p}-\mathrm{Akt}$ ) can inactivate GSK-3 $\beta$ by phosphorylation, alleviating the cerebral cell apoptosis. Another report showed that Bax is a direct downstream target of GSK-3 $\beta$, and GSK- $3 \beta$ exacerbates ischemic neuronal cell apoptosis by regulating the mitochondrial localization of Bax (36). Therefore we tested the effects of GSK-3 $\beta$ following 4-MCPC administration. Our study further tested if cerebral $\mathrm{I} / \mathrm{R}$ injury significantly decreased $\mathrm{p}$-Akt and $\mathrm{p}-\mathrm{GSK}-3 \beta$, which would be consistent with previous reports $(37,38) .4-\mathrm{MCPC}$ ( 4 and 8 $\mathrm{mg} \cdot \mathrm{kg}^{-1}$ ) remarkably increased $\mathrm{p}$-Akt and GSK-3 $\beta$ levels compared with the model group, indicating that the PI3K/Akt signal pathway may be involved in the neuroprotective effect of 4-MCPC in cerebral I/R injury.

Wortmannin is a specific PI3K inhibitor, which was widely used to study the PI3K/Akt signal pathway (39, 40). We also used wortmannin in our study to further examine whether 4-MCPC produces neuroprotective effects by activating the PI3K/Akt signal pathway. Our studies showed that treatment with 4-MCPC plus wortmannin significantly increased the neurological deficit scores, ischemic infarct volumes, and the number of apoptotic cells compared with 4-MCPC alone (Figs. 1 and 2). Western blot assay indicated that administration of 4-MCPC plus wortmannin remarkably increased the level of Bax and decreased the level of Bcl-2 and the ratio of $\mathrm{Bcl}-2 / \mathrm{Bax}$ compared with $4-\mathrm{MCPC}$ alone (Fig. 3). In addition, both p-Akt and p-GSK-3 $\beta$ in ischemic penumbra was lowered in 4-MCPC plus wortmannin group compared with the 4-MCPC $\left(8 \mathrm{mg} \cdot \mathrm{kg}^{-1}\right)$ group (Fig. 4). Collectively, our results further suggested that the neuroprotective effect of 4-MCPC was mediated by the PI3K/Akt signal pathway. Figure 5 shows the PI3K/Akt signal pathway related to our study.

Previous research has proved that the neuroprotective effect of muscone on cerebral $\mathrm{I} / \mathrm{R}$ injury in rats was obtained by inhibiting oxidative stress, calcium overload, and cell apoptosis. The mechanism may be related with reducing EEACl mRNA expression, decreasing activation of NMDA ( $N$-methyl-D-aspartate) receptor, $\mathrm{Ca}^{2+}$-CaMKII (calmodulin-dependent kinase II) and CaMKII-dependent ASK-1/JNK/p38 (apoptosissignalregulating kinase I / c-Jun NH2-terminal kinase / mitogen-activated protein kinase) signaling pathway, and regulation of the Bcl-2 family $(41,42)$. 4-MCPC, the isomeride of muscone, has similar neuroprotective effect on cerebral I/R injury. However the neuroprotective activity of 4-MCPC was exhibited via activating the PI3K/Akt signal pathway. It is generally known that inflammation plays a crucial role in cerebral I/R injury, 
and our previous study testified that 4-MCPC has potent anti-inflammatory activity via decreasing the levels of IL-1 $\beta$, TNF- $\alpha$, PGE2, and MPO (17). So we speculate that the neuroprotective effects of 4-MCPC may also be related with the anti-inflammatory effects. This is another study that we will investigate in the future.

\section{Conclusions}

In conclusion, our study proved for the first time that 4-MCPC protects against cerebral I/R injury by targeting the apoptosis-related proteins Bax and Bcl-2. The neuroprotective effects of 4-MCPC may be partly related with the activation of the PI3K/Akt signal pathway.

\section{Acknowledgments}

This work was supported by Shandong Hongjitang Pharmaceutical Group Co., Ltd., which provided 4-MCPC and financial support.

\section{Conflicts of Interest}

The authors declared no potential conflicts of interest.

\section{References}

1 Lo EH, Dalkara T, Moskowitz MA. Mechanisms, challenges and opportunities in stroke. Nat Rev Neurosci. 2003;4:399-415.

2 Shimazawa M, Hara H. Novel situations of endothelial injury in stroke-mechanisms of stroke and strategy of drug development: protective effects of antiplatelet agents against stroke. J Pharmacol Sci. 2011;116:30-35.

3 Silvestrelli G, Corea F, Paciaroni M, Milia P, Palmerini F, Parnetti L, et al. The Perugia hospital-based stroke registry: report of the 2nd year. Clin Exp Hypertens. 2002;24:485-491.

4 Guo C, Tong L, Xi MM, Yang HF, Dong HL, Wen AD. Neuroprotective effect of calycosin on cerebral ischemia and reperfusion injury in rats. J Ethnopharmacol. 2012;144:768774.

5 Ames A, Wright RL, Kowada M, Thurston JM, Majno G. Cerebral ischemia-the no-reflow phenomenon. Am J Pathol. 1968;52:437-453.

6 Ozbal S, Erbil G, Kocdor H, Tugyan K, Pekcetin C, Ozogul C. The effects of selenium against cerebral ischemia-reperfusion injury in rats. Neurosci Lett. 2008;438:265-269.

7 Neumar RW. Molecular mechanisms of ischemic neuronal injury. Ann Emerg Med. 2000;36:483-506.

8 Broughton BR, Reutens DC, Sobey CG. Apoptotic mechanisms after cerebral ischemia. Stroke. 2009;40:e331-e339.

9 Rehni AK, Singh N. Role of phosphoinositide 3-kinase in ischemic postconditioning-induced attenuation of cerebral ischemia-evoked behavioral deficits in mice. Pharmacol Rep. 2007;59:192-198.

10 Jope RS, Johnson GV. The glamour and gloom of glycogen kinase-3. Trends Biochem Sci. 2004;29:95-102.

11 Crowder RJ, Freeman RS. Glycogen synthase kinase-3 beta activity is critical for neuronal death caused by inhibiting phosphatidylinositol 3-kinase or Akt but not for death caused by nerve growth factor withdrawal. J Biol Chem. 2000;275:
34266-34271.

12 Namura S, Zhu J, Fink K, Endres M, Srinivasan A, Tomaselli $\mathrm{KJ}$, et al. Activation and cleavage of caspase-3 in apoptosis induced by experimental cerebral ischemia. J Neurosci. 1998;18: 3659-3668.

12 Tsujimoto Y, Shimizu S. Bcl-2 family: life-or-death switch. FEBS letters. 2000;466:6-10.

13 Lin DL, Chang HC, Huang SH. Characterization of allegedly musk containing medicinal products in Taiwan. J Forensic Sci. 2004;49:1187-1193.

14 Wu QB, Li HT, Wu Y, Shen WX, Zeng L, Cheng HB, et al. Protective effects of muscone on ischemia-reperfusion injury in cardiac myocytes. J Ethnopharmacol. 2011;138:34-39.

15 Sun R, Zhang W, Lv LL, Ren HY. Prorective effects of muscone on rats with complete cerebral ischemia. Traditional Chinese Drug Research \& Clinical Pharmacology. 2009;20:197-200.

16 Zhang ZR, Liu CJ, Bi LJ, Li HY, Li XF, Shi Q. Effect of 4-methyl-cyclopentadekanone on learning and memory in vascular dementia rats. Chinese Journal of Experimental Traditional Medical Formulae. 2012;20:228-230.

17 Ma YK, Li Y, Li XF, Wu YL. Anti-inflammatory effects of 4-methylcyclopentadecanone on edema models in mice. Int J Mol Sci. 2013;14:23980-23992.

$18 \mathrm{Xu} \mathrm{X}$, Chua CC, Gao J, Hamdy RC, Chua BH. Humanin is a novel neuroprotective agent against stroke. Stroke. 2006;37: 2613-2619.

19 Longa EZ, Weinstein PR, Carlson S, Cummins R. Reversible middle cerebral artery occlusion without craniectomy in rats. Stroke. 1989;20:84-91.

20 Sun BZ, Chen L, Wei XB, Xiang YX, Liu XQ, Zhang XM. The Akt/GSK pathway mediates flurbiprofen-induced neuroprotection against focal cerebral ischemia/reperfusion injury in rats. Biochem Bioph Res Co. 2011;409:808-813.

21 Ahmad A, Khan MM, Raza SS, Javed H, Ashafaq M, Islam F, et al. Ocimum sanctum attenuates oxidative damage and neurological deficits following focal cerebral ischemia/reperfusion injury in rats. Neurol Sci. 2012;33:1239-1247.

22 Devries AC, Nelson RJ, Traystman RJ, Hurn PD. Cognitive and behavioral assessment in experimental stroke research: will it prove useful? Neurosci Biobehav Rev. 2011;25:325-342.

23 Koistinaho J, Hokfelt T. Altered gene expression in brain ischemia. Neuroreport. 1997;8:1-8.

24 Rosse T, Olivier R, Monney L, Rager M, Conus S, Fellay L, et al. Bcl-2 prolongs cell survival after Bax-induced release of cytochrome c. Nature. 1998;391:496-499.

25 Yin J, Tu C, Zhao J, Ou DM, Chen GW, Liu Y, et al. Exogenous hydrogen sulfide protects against global cerebral ischemia/ reperfusion injury via its anti-oxidative, anti-inflammatory and anti-apoptotic effects in rats. Brain Res. 2013;1491:188-196.

26 Hata R, Gillardon F, Michaelidis TM, Hossmann KA. Targeted disruption of the Bcl-2 gene in mice exacerbates focal ischemic brain injury. Metab Brain Dis. 1999;14:117-124.

27 Oltvai ZN, Milliman CL, Korsmeyer SJ. Bcl-2 heterodimerizes in vivo with a conserved homolog, Bax, that accelerates programmed cell death. Cell. 1993;74:609-619.

28 Zhu Y, Prehn JH, Culmsee C, Krieglstein J. The beta2adrenoceptor agonist clenbuterol modulates Bcl-2, Bax-xl and Bax protein expression following transient forebrain ischemia. Neuroscience. 1999;90:1255-1263.

29 Li JS, Zhang W, Kang ZM, Ding SJ, Liu WW, Zhang JH, 
et al. Hyperbaric oxygen preconditioning reduces ischemiareperfusion injury by inhibition of apoptosis via mitochondrial pathway in rat brain. Neuroscience. 2009;159:1309-1315.

30 He Y, Wan HT, Du YG, Bie XD, Zhao T, Fu W, et al. Protective effect of Danhong injection on cerebral ischemia-reperfusion injury in rats. J Ethnopharmacol. 2012;144:387-394.

31 Zheng YQ, Hou JC, Liu JX, Yao MJ, Li L, Zhang B, et al. Inhibition of autophagy contributes to melatonin-mediated neuroprotection against transient focal cerebral ischemia in rats. J Pharmacol Sci. 2014;124:354-364.

32 Mullonkal CJ, Toledo-Pereyra LH. Akt in ischemia and reperfusion. J Invest Surg. 2007;20:195-203.

33 Kihara T, Shimohama S, Sawada H, Honda K, Nakamizo T, Kanki R, et al. Protective effect of dopamine D2 agonists in cortical neurons via the phosphatidylinositol 3 kinase cascade. J Neurosci Res. 2002;70:274-282.

34 Hanada M, Feng J, Hemmings, BA. Structure, regulation and function of PKB/AKT-a major therapeutic target. Biochim Biophys Acta. 2004;1697:3-16.

35 Fukunaga K, Kawano T. Akt is a molecular target for signal transduction therapy in brain ischemic insult. J Pharmacol Sci. 2003;92:317-327.

36 Linseman DA, Butts BD, Precht TA, Phelps RA, Le SS, Laessig TA, et al. Glycogen synthase kinase-3beta phosphorylates Bax and promotes its mitochondrial localization during neuronal apoptosis. J Neurosci. 2004;24:9993-10002.

37 Yu HL, Zhang ZL, Chen J, Pei AJ, Hua F, Qian XC, et al. Carvacro, a food-additive, provides neuroprotection on focal cerebral ischemia/reperfusion injury in mice. PLos One. 2012; 7:e33584.

38 Chen L, Qian LB, Ma LL, Yu J, Zhu AH, Wen CY, et al. Both PI3K/Akt and ERK1/2 pathways participate in the protection by dexmedetomidine against transient focal cerebral ischemia/reperfusion injury in rats. Brain Res. 2013;1494:1-8.

39 Wang HY, Wang GL, Yu YH, Wang Y. The role of phosphoinositide3-kinase/Akt patheway in propofol-induced postconditioning against focal cerebral ischemia-reperfusion injury in rats. Brain Res. 2009;1297:177-184.

40 Chen L, Xiang YX, Kong LJ, Zhang XM, Sun BZ, Wei XB, et al. Hydroxysafflor Yellow A protects against cerebral ischemiareperfusion injury by anti-apoptotic effect through PI3K/Akt/ GSK3 $\beta$ pathway in rat. Neurochem Res. 2013;38:2268-2275.

41 Liang H, Chen H, Gao Y, Cai DF. Study of protection of muscone against local cerebral ischemia. Chinese Traditional Patent Medicine. 2003;25:225-227.

42 Yu LC, Wang N, Zhang YF, Wang Y, Li J, Wu Q, Liu YF. Neuroprotective effect of muscone on glutamate-induced apoptosis in PC12 cells via antioxidant and $\mathrm{Ca} 2+$ antagonism. Neurochem Int. 2014;70:10-21. 